\title{
Synthesis and Phase Transition Behaviours of New Chalcone Derivatives
}

\author{
S. T. Ha and Y. W. Low \\ Department of Chemical Science, Universiti Tunku Abdul Rahman, Jln Universiti, Bandar Barat, 31900 Kampar, Perak, Malaysia
}

Correspondence should be addressed to S. T. Ha; hast_utar@yahoo.com

Received 16 May 2013; Revised 17 July 2013; Accepted 18 July 2013

Academic Editor: Alessandro Volonterio

Copyright (C) 2013 S. T. Ha and Y. W. Low. This is an open access article distributed under the Creative Commons Attribution License, which permits unrestricted use, distribution, and reproduction in any medium, provided the original work is properly cited.

\begin{abstract}
A series of new chalcone derivatives with a general formula of $\mathrm{C}_{11} \mathrm{H}_{27} \mathrm{COOC}_{6} \mathrm{H}_{4} \mathrm{COCH}=\mathrm{CHC}_{6} \mathrm{H}_{4} \mathrm{X}$ where $\mathrm{X}=\mathrm{F}, \mathrm{Cl}, \mathrm{Br}$, and $\mathrm{NO}_{2}$ were well synthesized and crystallized from organic solution. The physical properties as well as the chemical formulations of these compounds were determined by spectroscopic techniques (FTIR, and ${ }^{1} \mathrm{H}$ and ${ }^{13} \mathrm{C}$ NMR). Differential scanning calorimetry (DSC) and polarizing optical microscopy (POM) techniques were employed to study their transition temperatures and mesophase characteristics. DSC thermograms of compounds with fluoro and nitro substituents displayed direct isotropization and recrystallization during heating and cooling processes. Chloro and bromo analogues exhibited $\mathrm{Cr}_{1}$-to- $\mathrm{Cr}_{2}$ transition within the crystal phase region. It was also found that enone linkage showed fewer tendencies to exhibit mesomorphic property compared to imine linkage. However, when enone linkage is combined with other central linkages and additional phenyl rings, it turns conducive to mesomorphism.
\end{abstract}

\section{Introduction}

Chalcone is a compound consists of two aromatic rings linked by an unsaturated $\alpha, \beta$-ketone, with various substituents on the two aromatic rings. Chalcone could be easily found in most of the plants naturally and is an intermediate precursor of flavonoids and isoflavonoids [1]. It was reported to have wide range of applications in the fields of biology and biochemistry $[2,3]$ such as antitumor $[4,5]$, antiinflammatory [6-8], and antimalaria [9] agents. Besides, it is also reported in its photochemical and photophysical properties as well, including being used as photoalignment and photocrosslinking unit in polymerization process [10], fluorescent dyes, light-emitting diodes (LEDs), and so forth [11].

Liquid crystals with a chalcone central linkage are relatively rare. In the literature, there are several reports of mesogenic compounds having chalcone linkage. However, many years ago Chudgar and Shah [12] and Yeap et al. [13] have reported homologous series containing ester-chalcone linkages. Recently, Thaker et al. [14] have also synthesized mesomorphic compounds containing Schiff base-chalcone linkage. In our previous works, we have studied liquid crystals with a Schiff base central linkage and terminal halogen group [15-18]. It was found that the halogen substituents are able to influence the mesomorphic properties of the Schiff bases. In view of the outstanding behavior of chalcone, the polar halogen and nitro groups have been introduced to the existing core system. Here, we report a series of newly derived analogues (Figure 1), 1( $4^{\prime}$ - undecylcarbonyloxyphenyl)-3-(X-substituted phenyl)-2propen-1-one, where $\mathrm{X}$-substituted is 4-fluoro, 4-chloro, 4bromo, and 4-nitro.

\section{Experimental}

Dodecanoic acid, 4-fluorobenzaldehyde, 4-chlorobenzaldehyde, 4-nitrobenzaldehyde, 4-hydroxyacetophenone, N,Ndicyclohexylcarbodiimide, 4-bromobenzaldehyde, and 4dimethylaminopyridine were of analytical grade and were 


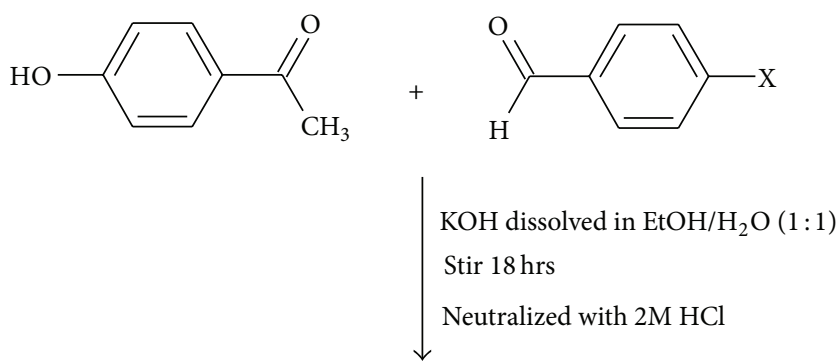

(c)

$\mathrm{C}_{11} \mathrm{H}_{23} \mathrm{COOH}$, DCC, DMAP

$\mathrm{CH}_{2} \mathrm{Cl}_{2} / \mathrm{DMF}$

Stir $12 \mathrm{hrs}$

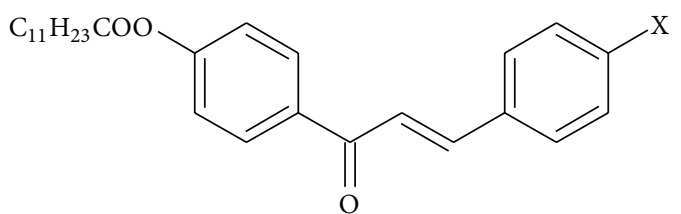

2a $(\mathrm{X}=\mathrm{F}) ; \mathbf{2 b}(\mathrm{X}=\mathrm{Cl}) ; \mathbf{2} \mathbf{c}(\mathrm{X}=\mathrm{Br}) ; \mathbf{2} \mathbf{d}\left(\mathrm{X}=\mathrm{NO}_{2}\right)$

Figure 1: Synthetic scheme towards formation of chalcones $\mathbf{2 a - d}$

used without further purification. The intermediate and title compounds were prepared according to previously reported methods [13].

FTIR data were acquired with a Perkin Elmer 2000FTIR spectrophotometer in the frequency range of 4000$400 \mathrm{~cm}^{-1}$ with samples embedded in $\mathrm{KBr}$ pellets. ${ }^{1} \mathrm{H}$ and ${ }^{13} \mathrm{C}$ NMR spectra were recorded in $\mathrm{CDCl}_{3}$ using a JEOL JNM ECP $400 \mathrm{MHz}$ NMR spectrometer with TMS as the internal standard.

The phase transition temperatures were measured using a Mettler Toledo DSC823 differential scanning calorimeter (DSC) at a scanning rate of $10^{\circ} \mathrm{C} \mathrm{min}^{-1}$. Optical texture studies were investigated by Carl Zeiss polarizing optical microscope attached to a Linkam Hot stage. The texture of the compounds was observed using polarized light with crossed polarizers, the sample being prepared as a thin film sandwiched between a glass slide and a cover. A video camera (Video Master coomo20P) was installed on the polarizing microscope and coupled to a video capture card (Video master coomo600), allowing real-time video capture and image saving.

2.1. Synthesis of 3-(X-Substituted Phenyl)-1-(4'-hydroxyphenyl)-2-propen-1-one $(\mathbf{1} \boldsymbol{a}-\boldsymbol{d}$, Where X-Substituted $=4$-Fluoro, 4-Chloro, 4-Bromo, and 4-Nitro, Respectively). Equimolar $(10 \mathrm{mmol})$ of 4-hydroxyacetophenone and 4-fluorobenzaldehyde were dissolved in an aqueous solution of potassium hydroxide (2.24 g in $15 \mathrm{~mL}$ of a mixture of ethanol/water $1: 1$ ). The mixture was stirred well for 18 hours. The solution was then neutralized with $20 \mathrm{~mL}$ of $2 \mathrm{M} \mathrm{HCl}$ in an ice bath. The product was filtered and recrystallized from ethanol.

2.2. Synthesis of 1-(4'-Undecylcarbonyloxyphenyl)-3-(4-chlorophenyl)-2-propen-1-one, $2 \boldsymbol{b}$. Equimolar (2 mmol) of compound $\mathbf{1 b}$ and dodecanoic acid were dissolved in $10 \mathrm{~mL}$ mixture of solvents DCM/DMF (1:1). DCC $(4 \mathrm{mmol})$ and DMAP $(0.4 \mathrm{mmol})$ were added to the mixture before it was stirred for an hour at $0^{\circ} \mathrm{C}$ and continued stirring for 12 hours at room temperature. The solution was filtered, and the filtrate was left standing overnight to evaporate the solvent. The crystals formed were then washed with petroleum ether and recrystallized by using ethanol. Compounds $\mathbf{2 a}, \mathbf{2 c}$, and 2d were prepared according to the similar method as that described for compound $\mathbf{2 b}$.

IR, ${ }^{1} \mathrm{H}$, and ${ }^{13} \mathrm{C}$ NMR data of the representative compound $\mathbf{2} \mathbf{b}$ are given as follows.

IR ( $\mathrm{KBr}) v_{\max } \mathrm{cm}^{-1} 3069\left(\mathrm{sp}^{2} \mathrm{C}-\mathrm{H}\right), 2916,2848(\mathrm{C}-\mathrm{H}$ aliphatic), 1753 ( $\mathrm{C}=\mathrm{O}$ ester), 1655, 1635 ( $\mathrm{C}=\mathrm{O}$ ketone), 1611, 1597 (C=C olefinic) 1222 (C-O ester). ${ }^{1} \mathrm{H}$ NMR $(400 \mathrm{MHz}$, $\left.\mathrm{CDCl}_{3}\right): \delta / \mathrm{ppm} 0.9\left(\mathrm{t}, 3 \mathrm{H}, \mathrm{CH}_{3}-\right), 1.3-1.4\left(\mathrm{~m}, 16 \mathrm{H}, \mathrm{CH}_{3}-\right.$ $\left.\left(\mathrm{CH}_{2}\right)_{8}-\right), 1.8$ (p, $\left.2 \mathrm{H},-\mathrm{CH}_{2}-\mathrm{CH}_{2}-\mathrm{COO}-\right), 2.6\left(\mathrm{t}, 2 \mathrm{H},-\mathrm{CH}_{2}-\right.$ COO-), $7.47(\mathrm{~d}, 1 \mathrm{H}$, olefinic- $\mathrm{H}), 7.75(\mathrm{~d}, 1 \mathrm{H}$, olefinic- $\mathrm{H})$, 7.23 (d, 2H, Ar-H), 7.39 (d, 2H, Ar-H), 7.57 (d, 2H, Ar-H), $8.05(\mathrm{~d}, 2 \mathrm{H}, \mathrm{Ar}-\mathrm{H}) .{ }^{13} \mathrm{C}$ NMR $\left(100 \mathrm{MHz}, \mathrm{CDCl}_{3}\right): \delta / \mathrm{ppm}$ 189.08 ( $\mathrm{C}=\mathrm{O}$ keto), 171.90 ( $\mathrm{C}=\mathrm{O}$ ester), 154.47, 136.61, 135.54, $133.38,130.19,129.71,129.37,122.00$ for aromatic carbons, $122.25,143.60$ for olefinic carbons, $34.52\left(-\mathrm{COO}-\mathrm{CH}_{2}-\right)$, $32.00\left(-\mathrm{COO}-\mathrm{CH}_{2}-\mathrm{CH}_{2}-\right), 29.69,29.54,29.43,29.34,29.18$ for methylene carbons $\left[-\left(\mathrm{CH}_{2}\right)_{6} \mathrm{CH}_{2} \mathrm{CH}_{2} \mathrm{CH}_{3}\right], 24.94$ ($\left.\mathrm{CH}_{2} \mathrm{CH}_{2} \mathrm{CH}_{3}\right), 22.78\left(-\mathrm{CH}_{2} \mathrm{CH}_{3}\right), 14.22\left(-\underline{\mathrm{CH}}_{3}\right)$.

\section{Results and Discussion}

3.1. Phase Transition Behaviours and Optical Texture Studies of Chalcone Derivatives. All of the compounds 2a-d were analyzed by DSC to study their thermal properties. It is used to determine whether a mesophase of liquid crystal is present in the compounds synthesized. DSC data upon heating and cooling cycles are tabulated in Tables 1 and 2, respectively. All members were nonmesogenic compounds. The representative DSC thermogram of compound $\mathbf{2 a}$ (Figure 2) showed single endotherm and exotherm, respectively, during both heating and cooling cycles. This observation indicates direct melting of the crystal phase to the isotropic liquid phase and vice versa. Under POM observation, crystal changed to dark region isotropic during heating run. No liquid crystal texture was observed during cooling process. However, the observation under polarized microscope showed the presence of subphases within the crystal region especially in compounds $\mathbf{2 b}$ and $\mathbf{2} \mathbf{c}$ of which the $\mathrm{Cr}_{1}$-to- $\mathrm{Cr}_{2}$ transitions occurred at 79.1 and $87.0^{\circ} \mathrm{C}$, respectively.

During the cooling cycle, compounds $2 \mathbf{a}$ and $\mathbf{2 d}$ directly crystallized into a stable state of crystal without any transition within the crystal region. However, compound $2 \mathrm{c}$ exhibited transition of $\mathrm{Cr}_{2}-\mathrm{Cr}_{1}$ within the crystal region at $81.7^{\circ} \mathrm{C}$ after 


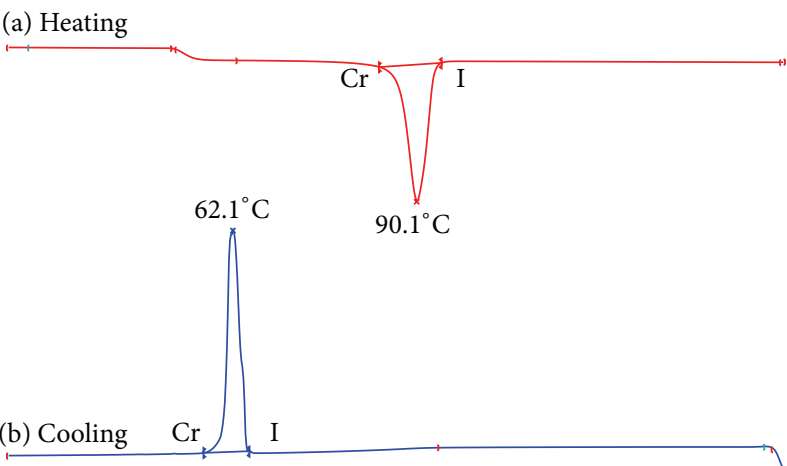

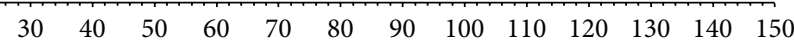

$\left({ }^{\circ} \mathrm{C}\right)$

FIGURE 2: DSC thermogram of compound 2a.

TABLE 1: Transition temperature and enthalpy changes of compounds $\mathbf{2 a - d}$ during heating cycle.

\begin{tabular}{lccc}
\hline Compounds & $\mathrm{Transition}$ & Temperature $\left({ }^{\circ} \mathrm{C}\right)$ & $\Delta H\left(\mathrm{~kJ} \mathrm{~mol}^{-1}\right)$ \\
\hline 2a & $\mathrm{Cr}_{1}-\mathrm{I}$ & 90.1 & 36.60 \\
2b & $\mathrm{Cr}_{1}-\mathrm{Cr}_{2}$ & 79.1 & 0.80 \\
& $\mathrm{Cr}_{2}-\mathrm{I}$ & 104.3 & 40.06 \\
\multirow{2}{*}{ 2c } & $\mathrm{Cr}_{1}-\mathrm{Cr}_{2}$ & 87.0 & 6.71 \\
& $\mathrm{Cr}_{2}-\mathrm{I}$ & 116.8 & 42.44 \\
2d & $\mathrm{Cr}_{1}-\mathrm{I}$ & 123.5 & 26.71 \\
\hline
\end{tabular}

TABLE 2: Transition temperature and enthalpy changes of compounds $\mathbf{2 a - d}$ during cooling cycle.

\begin{tabular}{lccc}
\hline Compounds & Transition & Temperature $\left({ }^{\circ} \mathrm{C}\right)$ & $\Delta H\left(\mathrm{~kJ} \mathrm{~mol}^{-1}\right)$ \\
\hline 2a & $\mathrm{I}-\mathrm{Cr}_{1}$ & 62.1 & -39.19 \\
& $\mathrm{I}-\mathrm{Cr}_{3}$ & 96.7 & -34.35 \\
2b & $\mathrm{Cr}_{3}-\mathrm{Cr}_{2}$ & 70.2 & -1.58 \\
& $\mathrm{Cr}_{2}-\mathrm{Cr}_{1}$ & 63.5 & -0.77 \\
& $\mathrm{I}-\mathrm{Cr}_{2}$ & 111.5 & -42.96 \\
2c & $\mathrm{Cr}_{2}-\mathrm{Cr}_{1}$ & 81.7 & -7.27 \\
& $\mathrm{I}^{2}-\mathrm{Cr}_{1}$ & 112.8 & -28.38 \\
\hline
\end{tabular}

it cooled from liquid state. For compound $\mathbf{2 b}$ (Figure 3), it also directly crystallized into crystalline state from isotropic liquid, but it undergoes 2 times transitions within the crystal region, which are $\mathrm{Cr}_{3}-\mathrm{Cr}_{2}$ at $70.2^{\circ} \mathrm{C}$ and $\mathrm{Cr}_{2}-\mathrm{Cr}_{1}$ at $63.5^{\circ} \mathrm{C}$.

3.2. Influence of Terminal Substituents on Thermal Properties of Chalcone Derivatives. The influence of terminal group on thermal stability can also be considered as one of the factors contributing towards the difference in melting temperature. Among compounds $\mathbf{2 a - 2 c}$, wherein each compound possesses the halogen in the aldehyde fragment, the melting temperature for compound $\mathbf{2} \mathbf{a}$ is very much lower in comparison with $\mathbf{2} \mathbf{b}$ and $\mathbf{2 c}$ (Figure 4 ). This comparison proposes

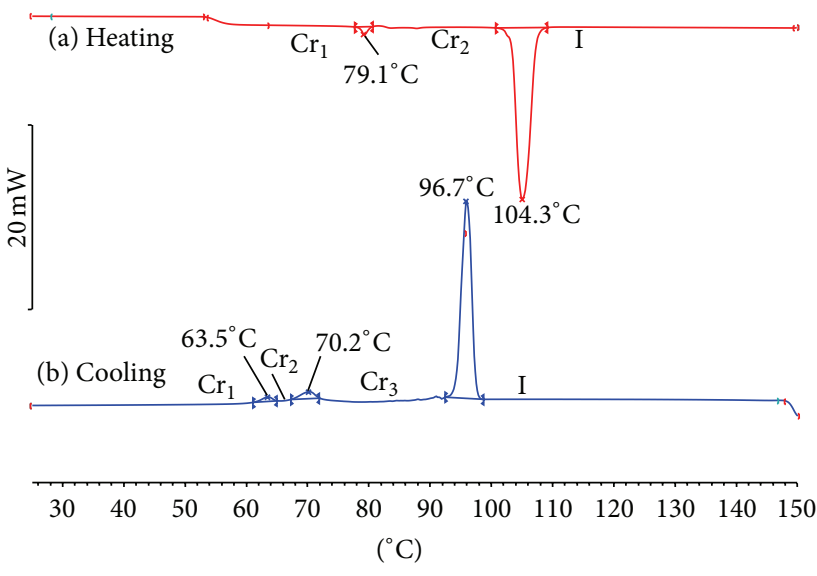

FIgURE 3: DSC thermogram of compound $\mathbf{2 b}$.

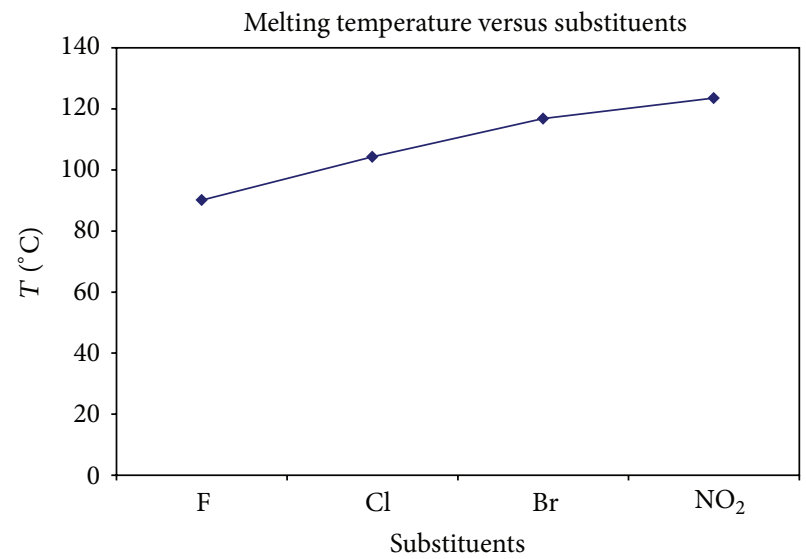

FIGURE 4: Graph of melting temperature versus terminal substituent of compounds $\mathbf{2 a - d}$.

TABle 3: Polarizability values of compounds $\mathbf{2 a}-\mathbf{d}$.

\begin{tabular}{lcc}
\hline Compounds & $\begin{array}{c}\text { Polarizability volume } \\
\left(\times 10^{-24} \mathrm{~cm}^{3}\right)\end{array}$ & Melting temperature $\left({ }^{\circ} \mathrm{C}\right)$ \\
\hline 2a & $49.46 \pm 0.5$ & 90.1 \\
2b & $51.40 \pm 0.5$ & 104.3 \\
2c & $52.51 \pm 0.5$ & 116.8 \\
2d & $52.06 \pm 0.5$ & 123.5 \\
\hline
\end{tabular}

that the fluorine (F) atom, which is the most electronegative, reduces the degree of molecular order. This thermal data also indicates that the influence of steric hindrance caused by the asymmetry of the central core of compound $2 \mathbf{a}$ is the least in comparison with compounds $\mathbf{2 b}$ and $\mathbf{2 c}$, which possess higher melting temperatures. This has also been confirmed by the polarizability values wherein the calculated polarizability (Table 3, calculated using ACD ChemSketch) increases from compound $2 \mathbf{a}\left[(49.46 \pm 0.5) \times 10^{24} \mathrm{~cm}^{-3}\right)$ to compound $2 \mathbf{b}\left[(51.40 \pm 0.5) \times 10^{24} \mathrm{~cm}^{-3}\right)$ and compound $2 \mathbf{c}$ $\left[(52.51 \pm 0.5) \times 10^{24} \mathrm{~cm}^{-3}\right)$. Melting point increases when polarizability of the compounds within the same series increases. 
TABLE 4: Comparison of compound $\mathbf{2 b}$ with other related compounds.

D<smiles>CCCCCCCCCCCCCCCCCC(C)(C)C</smiles><smiles>CCCCCCCCCCCCCCCCCCCCCCCCCC=Cc1ccc(OC(=O)c2ccccc2)cc1</smiles>

Cr 94.6 I

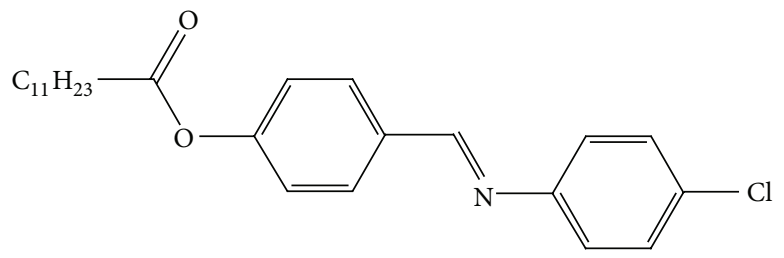

Cr 86.3 SmA 106.5 I

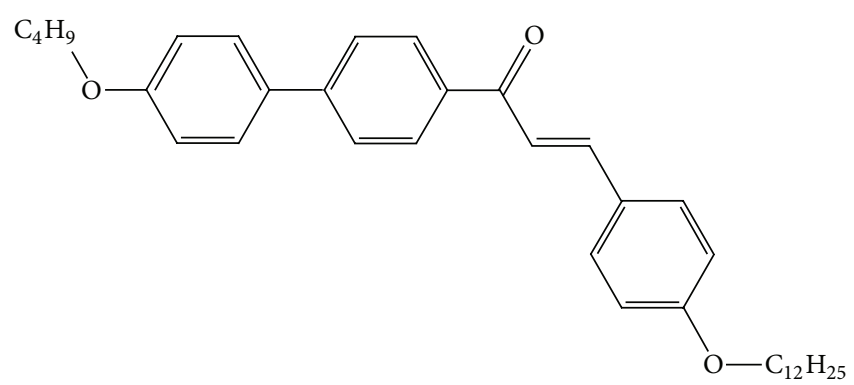

Cr 48 SmC 66 N $115 \mathrm{I}$<smiles>[R10]c1ccc(/C=C/C(=O)c2ccc(/N=C/c3ccc(O)cc3O)cc2)cc1</smiles>

Where $\mathrm{R}=\mathrm{C}_{12} \mathrm{H}_{13}-$

Cr 81 SmC 99 N 123 I
It needs to be pointed out that while the fluorine atom shows very low polarizability because the valence electrons residing at this atom are tightly held to the nucleus, bromine atom is considered to be larger than fluorine and hence is more easily polarized because electrons on this atom are far from the nucleus [20]. Compound 2d has the highest melting point probably due to the delocalization of electrons between the two oxygen atoms $\left(\mathrm{O}=\mathrm{N}^{+}-\mathrm{O}^{-}\right)$that increased the polarizability largely compared to $2 \mathbf{a}, \mathbf{2 b}$, and $\mathbf{2 c}$.

3.3. Structure-Mesomorphic Property Relationships. Molecular structure of organic compounds and their liquid crystalline properties are closely related. Table 4 summarizes the transition temperatures, mesomorphic behavior, and molecular structures of $\mathbf{2 b}$ and structurally related compounds reported in the literature $[13,14,16,19]$.

Compound A having enone $(-\mathrm{CH}=\mathrm{CH}-\mathrm{CO}-$ ) group as central linkage did not exhibit liquid crystal mesophase. This could be attributed to the enone group in chalcone consists of odd number atoms, thus is less conducive to mesomorphism compared to the linkages with even number atoms. Odd number atoms of linkages often cause a major problem to the mesogen, which is a nonlinearity in the linking group. By replacing enone group with imine linking 
group, higher linearity molecule of compound B exhibited smectic A phase. As calamitic liquid crystal requires its molecular axis to be linear for mesomorphism, this nonlinear linking group often causes the core to be deviated from its linear molecular axis [19]. Besides, the angular shape of keto group causes angle strain in the linking group, which makes the chalcone derivatives even less conducive to mesomorphism [21]. Therefore, we introduce a polar substituent $\left(\mathrm{F}, \mathrm{Cl}, \mathrm{Br}\right.$, and $\mathrm{NO}_{2}$ ) into the aldehyde fragment of chalcone structure in order to influence the phase behavior of existing chalcone. However, the introduction of terminal substituents is not sufficient to induce mesophase in chalcone. Incorporation of additional phenyl rings and imine linking group into compounds $\mathbf{C}$ and $\mathbf{D}$ caused the molecules to be longer and more linear. Both additional features are essential for inducing smectic $\mathrm{C}$ and nematic phases in compounds C and D.

\section{Conclusions}

A series of new chalcone derivatives, $1-\left(4^{\prime}\right.$ - undecylcarbonyloxyphenyl)-3-(X-substituted phenyl)-2-propen-1-one, has been synthesized and characterized. The physical properties as well as their mesomorphic behaviors were studied by using spectroscopic techniques (IR and NMR). It has been observed that enone $(-\mathrm{CO}-\mathrm{CH}=\mathrm{CH}-)$ linkage is less conducive to mesomorphism compared to $-\mathrm{CH}=\mathrm{N}-$ (imine) linkage due to the nonlinearity and angle strain arising from the keto group. The presence of polar terminal halogen and nitro substituent is unable to induce mesomorphism of chalcone derivatives. But when enone linkage is coupled with other central linkages and new phenyl rings, it becomes conducive to mesomorphism.

\section{Acknowledgments}

The authors would like to thank the Universiti Tunku Abdul Rahman and the Ministry of Higher Education Malaysia for the financial supports via LRGS (no. LR003-2011A) and the research facilities.

\section{References}

[1] G. Achanta, A. Modzelewska, L. Feng, S. R. Khan, and P. Huang, "A boronic-chalcone derivative exhibits potent anticancer activity through inhibition of the proteasome," Molecular Pharmacology, vol. 70, no. 1, pp. 426-433, 2006.

[2] S. N. A. Bukhari, M. Jasamai, I. Jantan, and W. Ahmad, "Reviews of methods and various catalysts used for chalcone synthesis," Mini-Reviews in Organic Chemistry, vol. 10, pp. 73-83, 2013.

[3] S. N. A. Bukhari, M. Jasamai, and I. Jantan, "Synthesis and biological evaluation of chalcone derivatives (mini review)," Mini Review of Medicinal Chemistry, vol. 12, no. 13, pp. 13841403, 2012.

[4] G. Saydam, H. H. Aydin, F. Sahin et al., "Cytotoxic and inhibitory effects of $4,4^{\prime}$-dihydroxy chalcone (RVC-588) on proliferation of human leukemic HL-60 cells," Leukemia Research, vol. 27, no. 1, pp. 57-64, 2003.
[5] L. Mishra, R. Sinha, H. Itokawa et al., "Anti-HIV and cytotoxic activities of $\mathrm{Ru}(\mathrm{II}) / \mathrm{Ru}(\mathrm{III})$ polypyridyl complexes containing 2,6-(2'-benzimidazolyl)-pyridine/chalcone as co-ligand," Bioorganic and Medicinal Chemistry, vol. 9, no. 7, pp. 1667-1671, 2001.

[6] H.-H. Ko, L.-T. Tsao, K.-L. Yu, C.-T. Liu, J.-P. Wang, and C.N. Lin, "Structure-activity relationship studies on chalcone derivatives: the potent inhibition of chemical mediators release," Bioorganic and Medicinal Chemistry, vol. 11, no. 1, pp. 105-111, 2003.

[7] P. Tuchinda, V. Reutrakul, P. Claeson et al., "Anti-inflammatory cyclohexenyl chalcone derivatives in Boesenbergia pandurata," Phytochemistry, vol. 59, no. 2, pp. 169-173, 2002.

[8] S. N. A. Bukhari, I. Jantan, and M. Jasamai, "Anti-inflammatory trends of 1, 3-diphenyl-2-propen-1-one derivatives," MiniReviews in Medicinal Chemistry, vol. 13, pp. 87-94, 2013.

[9] J. N. Domínguez, C. León, J. Rodrigues, N. G. De Domínguez, J. Gut, and P. J. Rosenthal, "Synthesis and evaluation of new antimalarial phenylurenyl chalcone derivatives," Journal of Medicinal Chemistry, vol. 48, no. 10, pp. 3654-3658, 2005.

[10] D. M. Shi, D. M. Song, K. H. Jung, and J. H. Moon, "Photochemical transformation of chalcone derivatives," Journal of Photoscience, vol. 8, no. 1, pp. 9-12, 2001.

[11] T. Suwunwong, Syntheses and fluorescent properties of chalcone derivatives and heteroarylchalcones [M.S. thesis], Prince of Songkla University, Thailand, 2010.

[12] N. K. Chudgar and S. N. Shah, "New fluorescent mesogens with a chalcone central linkage," Liquid Crystals, vol. 4, no. 6, pp. 661$668,1989$.

[13] G.-Y. Yeap, I. Susanti, B.-S. Teoh, W. A. K. Mahmood, and W. T. A. Harrison, "Synthesis and phase transition in new chalcone derivatives: crystal structure of 1-phenyl-3-( $4^{\prime}-$ undecylcarbonyloxyphenyl)-2-propen-1-one," Molecular Crystals and Liquid Crystals, vol. 442, pp. 133-146, 2005.

[14] B. T. Thaker, P. H. Patel, A. D. Vansadiya, and J. B. Kanojiya, "Substitution effects on the liquid crystalline properties of thermotropic liquid crystals containing schiff base chalcone linkages," Molecular Crystals and Liquid Crystals, vol. 515, pp. 135-147, 2009.

[15] H. Sie-Tiong, Y. Guan-Yeow, and B. Peng-Lim, "Synthesis and mesomorphic properties of new schiff base liquid crystals, N-[4-(4-n-Alkanoyloxybenzoyloxy)-2-Hydroxybenzylidene]4-Substituted-Anilines," Research Journal of Chemistry and Environment, vol. 15, no. 2, pp. 677-682, 2011.

[16] S.-T. Ha, L.-K. Ong, Y. Sivasothy et al., "Mesogenic schiff base esters with terminal chloro group: synthesis, thermotropic properties and X-ray diffraction studies," International Journal of Physical Sciences, vol. 5, no. 5, pp. 564-575, 2010.

[17] S. T. Ha, T. L. Lee, H. C. Lin et al., "Mesogenic Schiff base with bromo end group: synthesis and thermotropic properties," Asian Journal of Chemistry, vol. 24, no. 8, pp. 3679-3684, 2012.

[18] S.-T. Ha, T.-L. Lee, S.-L. Lee, S. Sreehari Sastry, and Y.-F. Win, "Schiff base liquid crystals with terminal iodo group: synthesis and thermotropic properties," Scientific Research and Essays, vol. 6, no. 23, pp. 5025-5035, 2011.

[19] B. T. Thaker and J. B. Kanojiya, "Synthesis, characterization and mesophase behavior of new liquid crystalline compounds having chalcone as a central linkage," Molecular Crystals and Liquid Crystals, vol. 542, pp. 84-98, 2011. 
[20] T. W. G. Solomons, Fundamentals of Organic Chemistry, John Wiley \& Sons, New York, NY, USA, 1994.

[21] N. H. Tinh, A. Zann, and J. C. Dubois, "Synthesis of 1-(4-alkoxy or alkyl-benzoyloxyphenyl)-2-( $4^{\prime}$-pentylphenyl)ethanes. Influence of the central group on the mesomorphic properties," Molecular crystals and liquid crystals, vol. 53, no. 1-2, pp. 43-54, 1979. 

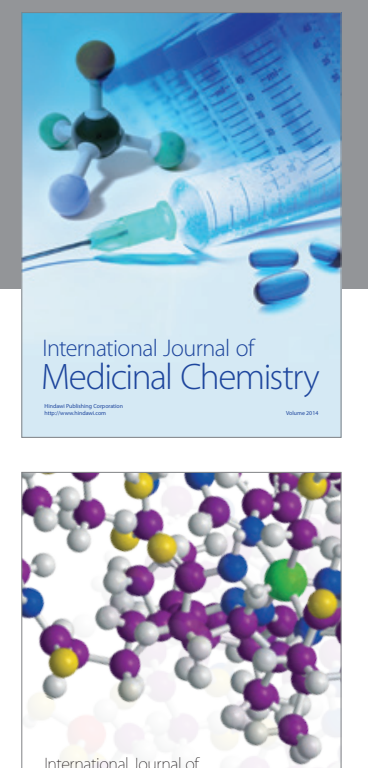

\section{Carbohydrate} Chemistry

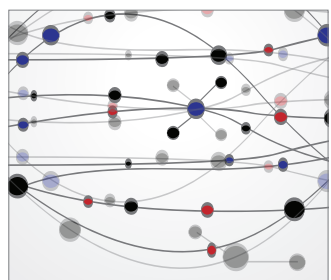

The Scientific World Journal

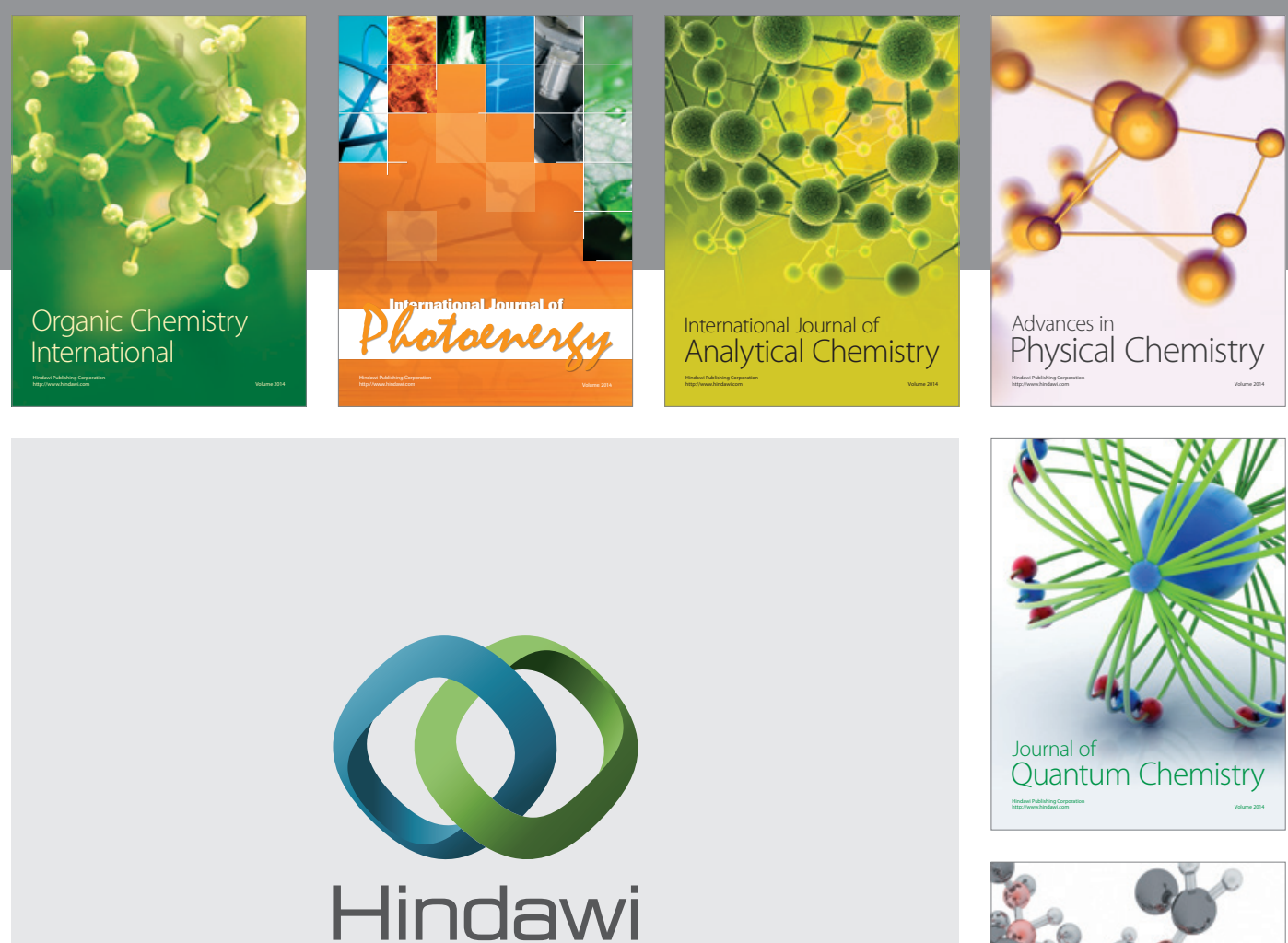

Submit your manuscripts at

http://www.hindawi.com

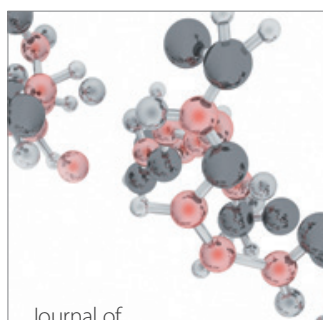

Analytical Methods

in Chemistry

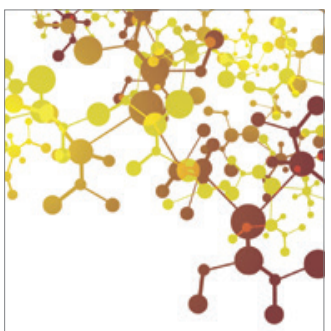

Journal of

Applied Chemistry

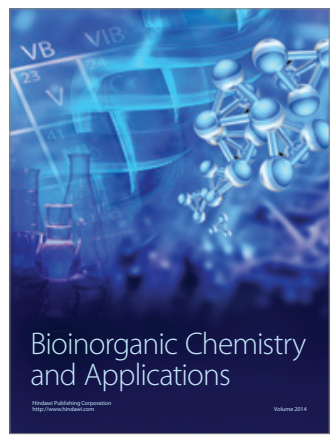

Inorganic Chemistry
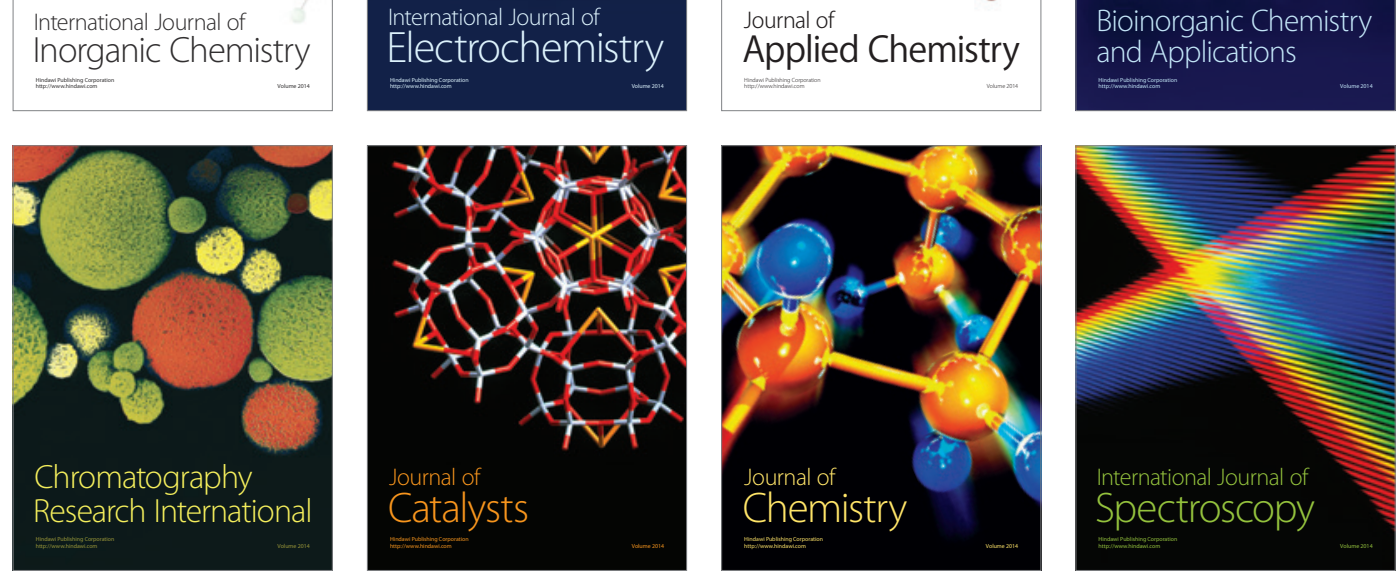